\title{
BREVE ENSAIO BIBLIOGRÁFICO EM TORNO DA OBRA DE GREGORY VLASTOS (À GUISA DE MANIFESTO)
}

\author{
Olimar Flores-Júnior* \\ É que de um relógio pra outro, \\ (...) \\ Tocar na banda, pra ganhar o quê? \\ Duas mariola e um cigarro Yolanda \begin{abstract}
no outro é quatro e meia. as hora "vareia"
\end{abstract}

Adoniran Barbosa. Tocar na Banda.
* Faculdade de Letras, Universidade Federal de Minas Gerais.

RESUMO: Este artigo apresenta, de forma breve e concisa, o percurso intelectual de Gregory Vlastos (1907-1991), com ênfase na sua extensa e variada produção escrita e na dependência - que constitui um verdadeiro método - entre esta e as suas intervenções orais, na forma de cursos, seminários e conferências em diversas instituições da Europa e da América. Pretende-se, a partir da trajetória deste que é reconhecidamente um dos mais importantes historiadores da filosofia antiga do último século, ensejar uma reflexão sobre as condições de execução e os modos de avaliação e aferição de qualidade do trabalho acadêmico.

PALAVRAS-CHAVE: Gregory Vlastos; história da filosofia antiga; produção bibliográfica; trabalho acadêmico.

\section{BREF ESS AI BIBLIOGR APHIQUE AUTOUR DE L'OEUVRE DE GREGORY VLASTOS (EN GUISE DE MANIFESTE)}

RÉSUMÉ: . Cet article présente, de façon brève et concise, le parcours intellectuel de Gregory Vlastos (1907-1991), en attirant l'attention sur l'étendue et sur la variété de sa production écrite, ainsi que sur la dépendance - qui s'impose alors comme méthode - entre celle-ci et ses interventions orales, sous la forme de cours, séminaires et conférences données à diverses institutions en Europe et en Amérique. On prétend, en partant de la carrière de celui qui a sans doute été un des plus grands historiens de la philosophie antique du siècle dernier, provoquer une 
réflexion sur les conditions de réalisation et sur les modes d'évaluation et de mensuration de la qualité du travail académique.

MOTS-CLÉS: Gregory Vlastos; histoire de la philosophie antique; production bibliographique; travail académique.

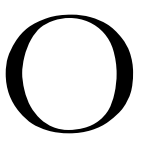

principal ensaio de Gregory Vlastos sobre o tema da ironia socrática constitui, como se sabe, o primeiro capítulo de seu Socrates, ironist and moral philosopher, publicado originalmente em 1991. ${ }^{1}$ Enfeixados por uma introdução e um epílogo, que leva um sugestivo título - Felix Socrates (Socrate le bienheureux, na tradução francesa e que, em português, poderia ser vertido como "Sócrates, o bem-aventurado") -, encontramos aí oito capítulos, tratando todos do homem que ganhou vida, para além da sua própria, nas páginas de Platão, Xenofonte e Aristófanes; segue-se a esse núcleo principal uma série de trinta e uma "notas adicionais" sobre temas afins, compondo um volume de mais de quatrocentas páginas que - coisa rara nas abordagens de fatura analítica - colocam a serviço do rigor filológico e da densidade dos argumentos filosóficos um texto elegante e fluente. O livro, que aparece no ano mesmo da morte de seu autor, representa, num certo sentido e por razões que o próprio Vlastos expôs, o eixo em torno do qual se organizaram os esforços do filósofo e do historiador da filosofia, cujo método de investigação fazia justamente convergir dois domínios considerados com frequência como distintos o bastante para parecerem inconciliáveis, o da filosofia e o da história da filosofia. $\mathrm{Na}$ introdução (How this book came to be), em que Vlastos busca explicar a gênese da obra, e em que compreensivelmente se imiscui uma breve narrativa de seu percurso intelectual, podemos ler: "O livro demorou muito tempo para nascer. Tudo começou por um falso começo. Por sorte, eu tinha obtido em 1953 a dispensa de todas as obrigações didáticas durante um ano (...) para estudar a filosofia de Platão e estava livre para proceder como bem entendesse". O "privilégio" concedido a Vlastos atualizava, de modo muito prático, a máxima do jovem Schelling, escrita numa carta a Hegel, segundo a qual "o alfa e o ômega de toda a filosofia é a liberdade". ${ }^{3}$ Atualizava enfim, para voltar aos gregos tão caros a Vlastos, a definição aristotélica de sabedoria como o tipo de conhecimento que existe em vista de si mesmo e que é privilégio dos seres livres. Suspeitando, por isso mesmo, que a sabedoria talvez não

\footnotetext{
${ }^{1}$ VLASTOS, G. Socrates, Ironist and Moral Philosopher. Ithaca, New York: Cornell University Press, 1991 (aqui indicado como SIMP). Tradução francesa: VLASTOS, G. Socrate. Ironie et philosophie morale. Traduit de l'anglais par Catherine Dalimier. Paris: Aubier, 1994.

${ }^{2}$ Salvo indicação contrária, todas as passagens das obras citadas foram traduzidas por mim. Em particular, para a tradução das passagens de Socrates, Ironist and Moral Philosopher, consultei, além do original, a versão francesa referida na nota precedente. Os itálicos e grifos nas citações dessas passagens são também de minha responsabilidade.

${ }^{3}$ SCHELLING, F. W. J. Carta a Hegel, 4 de fevereiro de 1795. (Briefe an und von Hegel, ed. J. Hoffmeister. Hambourg: Meiner, 1969, t. I, p. 22).
} 
fosse algo próprio do homem - "pois a natureza do homem é escrava em muitos aspectos"

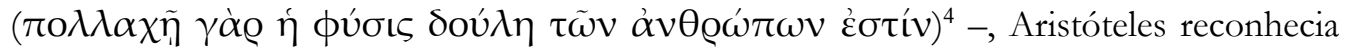
que a liberdade se impõe como o horizonte ideal do único terreno no qual a filosofia pode existir.

São essas coisas bem conhecidas, mas em muitos casos o óbvio só é ouvido quando gritado muitas vezes: a liberdade, que se opõe ao servilismo de objetivos externos e dados de antemão, confere a todo trabalho regras próprias de realização e produção.

Naquele ano de 1953, liberado de todo encargo didático e podendo proceder como bem entendesse, Vlastos publicou um único artigo ("Isonomia", no American Journal of Philology que foi, aliás, retrabalhado posteriormente e republicado em 1964, sob o título de "Isonomia politikée") e três resenhas de livros, à época, mais ou menos recentes (Man and the State [1951] de Jacques Maritain, Pytahgoreans and Eleatics [1948] de J. E. Raven e L'école éléate [1950] de Jean Zaphiropoulos): um artigo e três resenhas, marca bem inferior à de outros anos, como por exemplo o ano de 1969 que viu aparecer nada menos do que seis textos originais. ${ }^{6} \mathrm{~A}$ informação, na verdade, deveria surpreender de modo inverso: tendo ao seu dispor um ano inteiro para se consagrar exclusivamente à pesquisa, Vlastos ainda publicou um artigo e três resenhas (um material que obviamente poderia ter sido finalizado antes: o ano de publicação de um trabalho não coincide necessariamente com o ano de sua elaboração; o mais comum é que não seja assim). Por outro lado, considerando o conjunto de sua produção bibliográfica, contamos pouco mais de 120 títulos distribuídos em 62 anos

\footnotetext{
${ }^{4}$ ARISTÓTELES. Metafísica A, 2, 982b 29-30.

${ }^{5}$ VLASTOS, G. Isonomia politiké. In: MAU, J.; SCHIMIDT, E. G. (Ed.). Isonomia: Studien zur Gleichheitsvorstellung im griechischen Denken. Berlin: Akademie-Verlag, 1964. p. 1-35.

${ }^{6}$ VLASTOS, G. Justice and psychic harmony in the Republic. Journal of Pbilosophy, v. 66, p. 505-521, 1969, (reaproveitado em id., "Justice and happiness in the Republic", in: id. (ed.), Plato: A Collection of Critical Essays II: Ethics, Politics and Philosophy of Art and Religion. Garden City, New York: Doubleday \& Co., 1971, p. 66-95, este último reeditado em id., Platonic Studies. Princeton: Princeton University Press, 1973, p. 111-139); id., "Plato’s 'Third Man' argument (Parm,132a1-b2)", Philosophical Quarterly 19, 1969, p. 289-301 (republicado, com revisões, em id, Platonic Studies, cit., p. 342-365); id., "Pre-Socratic philosophy", in: Encyclopedia Americana, v. 22, New York: Americana Corporation, 1969; id., "Reasons and causes in the Phaedo", Philosophical Review, v. 78, p. 132-166, 1969 (republicado em id., Platonic Studies, cit., p. 76-110); id., Self-predication in Plato's later period", Philosophical Review, v. 78, p. 74-78, 1969, (republicado em id., Platonic Studies, cit., p. 335-341); id., "Socrates on acrasia", Phoenix, v. 23, p. 71-88, 1969 (republicado em id., Studies in Greek Philosophy, v. II: Socrates, Plato and their tradition, edited by Daniel W. Graham. Princeton: Princeton University Press, 1995, p. 43-59). Para o repertório da obra escrita de Gregory Vlastos, recorri principalmente à seção "Bibliography; the Works of Gregory Vlastos", provida por Daniel W. Graham em G. Vlastos, Studies in Greek Philosphy, v. II: Socrates, Plato and their tradition, cit., p. 325-330. Obviamente esta lista não noticia os trabalhos (re)publicados posteriormente à primeira edição deste livro, de 1995. É o caso, por exemplo, de "Socrates", em M. Canto-Sperber (dir.), Philosophie Grecque. Paris: P.U.F., 1998, p. 123-142 (1ª ed. 1997), versão francesa de um texto publicado originalmente em Proceedings of the British Academy, v. 74, p. 89-111, 1988, este mesmo suplantado pelos capítulos 2 e 3 de SIMP, p. 45-106.
} 
de carreira (Vlastos nasceu em 27 de julho de 1907 e morreu em 12 de outubro de 1991); sua primeira contribuição acadêmica, um comentário à filosofia daquele que viria a ser seu professor e orientador de sua tese de $\mathrm{PhD}$ (grau obtido em 1931, com um trabalho intitulado God as a Metaphisical Concept ${ }^{7}$ ), Alfred North Whitehead (a quem devemos a caracterização da tradição filosófica europeia como uma série de notas de rodapé aos textos de Platão), data de 1929. ${ }^{8}$ O cálculo não é difícil: uma média de menos de duas publicações anuais - e nesse cálculo deveria ser levado em conta ainda o fato de que no número total dessas publicações se incluem os (muitos) textos republicados (em alguns casos mais de uma vez), inclusive postumamente, sem nenhuma alteração ou com alterações mais ou menos importantes. ${ }^{9}$ Essa curiosa e aproximativa contabilidade, que no entanto lembra de perto uma realidade que não nos é estranha, com certeza soaria aos ouvidos de Vlastos como de muito mau gosto. Ele mesmo publicou, em 1980, em um volume organizado por William Frankena, um texto intitulado "Educação superior em ciências humanas: reflexões e propostas" em que, examinando as tendências do ensino universitário nos Estados Unidos, deplorava o fato de que em pesquisa, sobretudo no domínio das humanidades, a quantidade, que é aquilo que se conta e que oferece um critério de avaliação facilmente aplicável, pudesse contar mais do que a qualidade. ${ }^{10}$

A obra escrita de Gregory Vlastos não surgiu, portanto, com uma regularidade rigorosa: houve anos extremamente produtivos - e, convém insistir, ano produtivo, aqui, indica apenas aquele em que algum texto foi publicado e não deve de modo algum ser confundido com ano de trabalho intenso, já que o que se publica em um ano é normalmente o fruto do trabalho do ou dos anos anteriores, sem falar nas vicissitudes dos processos editorais que podem simplesmente atrasar a publicação de um texto já pronto (no nosso caso, a mais recorrente dessas vicissitudes é a prosaica, mas decisiva, falta de dinheiro que frequentemente assola nossas editoras universitárias e nossos periódicos científicos) - e outros nem tanto.

\footnotetext{
${ }^{7} \mathrm{O}$ tema escolhido por Vlastos não deve surpreender; bem ao contrário, ele reflete o foco de seus interesses em seu início de carreira: em 1929 (aos vinte e dois anos de idade, portanto) ele obtém o título de Bacharel em Teologia pela Universidade de Chicago (na Divinity School) e, no mesmo ano, é ordenado pastor. Vlastos, oriundo de uma família protestante, foi um militante cristão muito ativo, que buscava nesse sentido coadunar suas convicções políticas e filosóficas com sua crença religiosa. No curso dos anos 30 ele publica, entre outros textos, The religious way (New York: Women's Press, 1934); "What is Love?" (Chistendom, v. 1, p. 117-131, 1935); "Jesus' conflict with the Pharisees" (Christendom, v. 2, p. 86-100, 1937); uma resenha crítica do livro An interpretation of Christian Ethics (1935), de Reinhold Niebuhr (Christendom, v. 1, p. 390-394, 1935); e coeditou, com R. B. Y. Scott, o volume Towards the Christian Revolution (Chigaco; Willett, Clark and Co., 1936), no qual assina ainda "The ethical foundation" (p. 51-74).

${ }^{8}$ VLASTOS, G. Whitehead, critic of abstractions (being the story of a philosopher who started with science and ended with metaphysics). The Monist, v. 39, p. 170-203, 1929.

${ }^{9}$ Veja-se, por exemplo, a nota 6 supra.

${ }^{10}$ VLASTOS, G. Graduate education in the Humanities: reflections and proposals. In: FRANKENA, W. (Ed.). The Philosophy and Future of Graduate Education. Ann Arbor: University of Michigan Press, 1980. p. 64-81.
} 
Assim, anos como o já mencionado 1969, ou ainda $1946{ }^{11}$ ou $1965,{ }^{12}$ refletindo sem dúvida a inquietação e o vigor de uma juventude prolongada, convivem na bibliografia de Vlastos pacificamente com aqueles anos - poucos, é bem verdade - em que absolutamente nada foi publicado, como é o caso, por exemplo, do biênio 1943-1944, ${ }^{13}$ de 1951, ou 1976. Aliás, 1976 é precisamente o ano em que Vlastos se aposenta da Universidade de Princeton. Seria compreensível, e mesmo natural, que a partir desse momento, houvesse a cessação ou, ao menos, uma diminuição importante de suas atividades. O que se constata no entanto é que essa aposentadoria, nos termos do próprio Vlastos, não significou para ele uma "sentença de morte civil". ${ }^{14}$ Ele continuou a assumir o compromisso de novos cursos, seminários e conferências em instituições dos Estados Unidos, do Canadá, da Inglaterra e da Escócia, para graduandos, pós-graduandos, professores e pesquisadores, entre os quais se contavam não apenas estudiosos no domínio da filosofia e dos estudos clássicos, mas também no das humanidades em geral e em outras áreas do saber, havendo ainda, eventualmente, a presença de um público sem qualquer ligação com os meios universitários. ${ }^{15}$

\footnotetext{
${ }^{11}$ Neste ano, foram publicados os seguintes títulos: VLASTOS, G. Ethics an physics in Democritus II. Philosophical Review, v. 55, p. 53-64, 1946; VLASTOS, G. On the pre-history in Diodorus. American Journal of Philology, v. 67, p. 51-59, 1946; VLASTOS, G. Parmenides' theory of knowledge. Transactions and Proceedings of the American Philological Association, v. 77, p. 66-77, 1946; e VLASTOS, G. Solonian Justice. Classical Philology, v. 41, p. 65-83, 1946.

${ }^{12}$ VLASTOS, G. Anamnesis in the Meno. Dialogue, v. 4, p. 143-167, 1965; VLASTOS, G. Creation in the Timaeus: is it a fiction? In: ALLEN, R. E. (Ed.). Studies in Plato's Metaphysics. London: Routledge \& Kegan Paul, 1965, p. 401-419; VLASTOS, G. Degrees of reality in Plato. In: BAMBROUGH, R. (Ed.). New Essays in Plato and Aristotle. London: Routledge \& Kegan Paul, 1965, p. 1-19; VLASTOS, G. Minimal parts in Epicurean atomism. Isis, v. 56, p. 121-147, 1965.

${ }^{13}$ Aqui uma ressalva se impõe: durante a Segunda Guerra, compreendendo portanto os anos em questão, Vlastos serviu, na qualidade de cidadão canadense (ele era turco de nascimento), na Royal Canadian Air Force, como líder de esquadrão da Divisão de Pessoal. Nessa ocasião, ele exerceu também a função de editor da Canadian Affairs, uma publicação da agência Wartime Information Board.

${ }^{14}$ Cf. SIMP, p. 10.

${ }^{15}$ Cf. SIMP, p. 12. Vlastos aparentemente guardou intactas, na aposentadoria, as convicções que tinha em seu começo de carreira. Ainda na introdução de SIMP podemos ler: "Pediram-me para escrever uma introdução ao Protágoras para a Liberal Arts Press. A coleção de clássicos dessa editora visava o público dos primeiros anos de universidade., um público ao qual eu tinha me dirigido com enorme prazer nos meus cursos de graduação por mais de vinte anos, primeiro no Queen's College, no Canadá, depois na Cornell University e, mais uma vez, em Princeton. Sem saber grego, avessos a detalhes técnicos, impacientes com a parafernália das pesquisas que todavia eles respeitavam, esses estudantes reagiam com ardor quando eram pegos no mundo em que viviam. Foi o estilo que eu adotei naquela introdução [cf. Vlastos, G. Plato's Protagoras. New York: Liberal Arts Press, 1956] (...). Aquele Sócrates estava vivo. Eu mantive o mesmo estilo no ano seguinte ao me dirigir à Humanities Association of Canada (...). Mais uma vez, eu falava para colegas não-especialistas. Diante de um público oriundo de setores muito diferentes do mundo acadêmico, eu descrevia os perigos da docta ignorantia, maior do que nunca na nossa época tomada por uma pesquisa profissionalizada, dispersa, fragmentada, minusculamente [minutely] especializada. Deplorando o modo como o scholar se alienou
} 
É justamente neste período pós-Princeton, em especial por ocasião do convite para ministrar, em 1981, as Gifford Lectures da Universidade de St. Andrews, cujo contrato de trabalho convidava à publicação das conferências proferidas, mas não fazia disso uma exigência, ${ }^{16}$ que Vlastos pôde aprofundar certas questões em torno do Sócrates platônico que, malgrado os esforços dispendidos naquele ano sabático de 53, ainda não tinham recebido uma resposta satisfatória. Decorre daí o fato de que as intervenções de Vlastos na Universidade de St. Andrews representaram um marco importante na elaboração de seu SIMP e, por extensão, na constituição de sua carreira como professor; além de, de certo modo, indicar o que poderiam ser as condições ideais do trabalho intelectual (com os percalços que lhe são inerentes), tal como o próprio Vlastos o concebia. As palavras com as quais ele descreve aquela experiência são, nesse sentido, reveladoras: "Embora eu soubesse que as pessoas em St. Andrews esperavam de mim uma performance rigorosamente acabada, eu consumi os três anos de preparação que me foram acordados apenas na tarefa preliminar de clarificar minha própria compreensão do tema. (...). Eu cheguei a St. Andrews tremendo em meus sapatos, certo de não estar, no que dizia respeito à preparação das minhas conferências, nem perto do nível necessário para que elas fossem dignas de publicação". ${ }^{17}$ Essa declaração, que, numa leitura apressada, poderia ser equivocadamente entendida como a admissão de uma bem humana falibilidade, como a confissão bem humorada de uma negligência episódica ou como uma espécie de captatio benevolentiae retroativa, explicita, na verdade, um método de trabalho já em curso, que reafirma a essência dialética da reflexão e o fato de que em ciências humanas o solipsismo tem raro valor. Trata-se, em termos práticos, da necessidade de se submeter uma ideia ou a interpretação de um objeto qualquer (no caso da história da filosofia, um texto) ao crivo de um debate real, enquanto a forma da escritura, trazida à sua devida importância, apenas sedimenta o processo. ${ }^{18}$ Vlastos prossegue: "As conferências foram escritas e podiam ter sido publicadas imediatamente. Mas a reflexão estava longe de

do resto da humanidade, eu dizia [Vlastos, G. "The paradox of Socrates", Queen's Quarterly, v. 64, p. 496-516, 1957-1958, (cf. p. 497)] que na minha exposição eu gostaria de oferecer 'humanismo, e não erudição [scholarship], arriscando-me numa definição marota de 'humanismo' como 'um scholar que se esforça com afinco em ser humano; tentando, primeiro, achar a relevância de seu trabalho individual para o comum dos mortais; segundo, comunicando suas descobertas na língua ordinária - não na língua popular, mas simplesmente numa língua correta [the Queen's English], sem recurso a um rosário de termos técnicos'. Seria realmente possível fazer um trabalho de erudição e praticar esse tipo de humanismo ao mesmo tempo? Eu não tenho como ter certeza. Mas é nisso que eu me empenhava naquela ocasião, e não desisti neste livro, embora a tarefa pareça mais difícil agora, pois este trabalho deverá pender mais pesadamente para o lado da erudição" (p. 2-3).

${ }^{16}$ Cf. SIMP, p. 12.

${ }_{17}$ SIMP, p. 11-12.

${ }^{18}$ Dessa perspectiva, não terá sido por simples formalidade, polidez ou humildade protocolar que Vlastos consigna, na abertura de SIMP, a seguinte dedicatória: "I dedicate this book to colleagues and students whose partnership has shaped my search: Berkeley (1979-87), Cambridge (1983-4), Cornell (1986), St. Andrews (1981), Toronto (1978)". 
ter chegado a seu termo (...). Faltava ao trabalho que eu trouxera a St. Andrews aquilo que eu devia aprender ali, através das reações do público". ${ }^{19}$

Uma dessas reações, expressa por Ian Kidd, apontava uma falha histórica na tese de Vlastos, segundo a qual haveria uma relação de identidade entre felicidade e virtude na filosofia moral de Sócrates, tal como exposta no relato platônico, o que implicaria abolir as diferenças entre a perspectiva socrática e a moral estoica formulada posteriormente. Embora sua interpretação viesse apoiada numa análise criteriosa dos textos, Vlastos aquiesce à pertinência da crítica, mas pondera que encontrar os termos exatos pelos quais a relação entre virtude e felicidade no pensamento do Sócrates platônico devem ser compreendidos seria uma tarefa que demandaria ainda um longo trabalho. De fato, a resposta ao problema, aquela que Vlastos julgará satisfatória, aparece três anos mais tarde, em 1984, numa conferência proferida em Cambridge ${ }^{20}$ mas a sua forma escrita definitiva, substancialmente modificada, deveria esperar ainda outros sete anos para vir à luz, como o oitavo capítulo de SIMP.

Esses fatos demostram que, se o trabalho de Vlastos, quantitativamente admirável tanto em sua vertente escrita quanto em suas intervenções orais, não se destaca pelo ritmo constante de suas publicações, ele é marcado por um outro tipo de regularidade - e nisso há um consenso que reúne tanto seus seguidores quanto seus críticos mais veementes ${ }^{21}-$, a da consistência, do vigor e do rigor de sua reflexão. Malheur au vague, mieux vaut le faux - "mais vale o falso do que o vago", numa tradução livre -, eis um adágio que Vlastos costumava citar e que, de toda evidência, norteava o seu trabalho. Nesse sentido, a carreira de Vlastos nos convida ao risco de uma generalização: no que tange ao trabalho intelectual, a presença deste traço qualitativo só pode ser verificada na ausência daquele, meramente quantitativo.

Vlastos, como já se escreveu, foi responsável pela elevação dos padrões de pesquisa, análise e exposição da filosofia clássica a novos níveis de excelência. No que respeita à metodologia, ele resgatou a importância da filosofia antiga e, consequentemente, da história da filosofia, para a filosofia, sobretudo em ambiente anglo-saxão do pós-guerra que sofria a influência de doutrinas como a do primeiro Wittgenstein, para quem o mundo seria um conjunto de fatos independentes uns dos outros, compreensíveis em seu estado pela análise dos enunciados que buscavam descrevê-los. ${ }^{22}$ Do mesmo modo, mas em sentido inverso, ele submeteu os textos filosóficos da Antiguidade aos instrumentos fornecidos pela filologia e pela filosofia analítica, apresentando-os sob uma nova luz. É o que observa, simplificando as coisas com alguma ironia, o editor de seus dois volumes póstumos de estudos sobre a filosofia grega, Daniel Graham: "A nova filosofia que veio a dominar a cena americana

\footnotetext{
${ }^{19}$ SIMP, p. 12.

${ }^{20}$ Vlastos, G. Happiness and virtue in Socrates' moral theory. Proceedings of the Cambridge Philological Society, n. 30, 1984, p. 181-213 (republicado em Topoi, v. 4, p. 3-22, 1985).

${ }^{21}$ É o caso, por exemplo, de Monique Dixsaut. Veja-se a propósito o volume VLASTOS, G.; DIXSAUT, M. Refutação. Traduções e introdução de Janaína Mafra. São Paulo: Paulus, 2012.

${ }^{22}$ Vlastos se serve, aliás, da mudança de perspectiva que Wittgenstein adota ao longo de sua carreira para ilustrar as mutações ao longo da filosofia de Platão que comprometem, por assim dizer, a unidade da personagem Sócrates: cf. VLASTOS, G. The evidence of Aristotle and Xenophon, SIMP, p. 81-106.
} 
depois da II Guerra Mundial, era predominantemente a- ou anti-histórica (...). Assim, todos os problemas filosóficos eram problemas de linguagem (numa versão ou noutra) e o filósofo devia analisar conceitos apropriados ou fragmentos de discurso para chegar a alguma clarificação. Não havia aí espaço para a história da filosofia - nenhum espaço na tradição dos positivistas lógicos do círculo de Viena, para quem a única história relevante era a da ciência corretamente explicada; nenhum espaço em Wittgenstein, que raramente se permitia a leitura de outros filósofos; e apenas um espaço limitado em Bertrand Russell, na medida em que a história da filosofia pudesse antecipar distinções modernas. A filosofia consistia (...) em ensaios incisivos sobre conceitos abstratos usando a lógica simbólica ou outras ferramentas de análise, em textos sem notas de rodapé ou bibliografias, escritos por autores com sobrenomes anglo-saxônicos e as iniciais". E Graham continua explicando que "o que Vlastos fez foi se apropriar das ferramentas da nova filosofia e da filologia e aplicálos aos textos antigos, para mostrar que os filósofos gregos eram filósofos com quem os analíticos modernos podiam dialogar. Ele demonstrou que pode se ter filosofia e história, argumentos e notas de rodapé, sofisticação lógica e rigor filológico. Não que filosofia e filologia nunca tivessem cooperado antes, ${ }^{23}$ mas o que Vlastos promoveu foi um modelo - um paradigma - para o casamento de disciplinas que seguiriam a nova filosofia analítica. Nesse processo a filosofia antiga tornou-se simplesmente filosofia". Como prova concreta do papel desempenhado por Vlastos nessa mudança de perspectiva, bastaria lembrar da publicação, em 1954, de seu "The Third Man Argument in the Parmenides", ${ }^{24}$ que provocou uma viva reação, não só por parte dos historiadores da filosofia e dos "classicistas" em geral, mas também por parte de filósofos tout court, como Wilfrid Sellars e Peter Geach. ${ }^{25}$

Firmada a indiscutível importância de Gregory Vlastos como um marco teórico no âmbito da filosofia antiga, e em especial no dos estudos socráticos, dois traços de sua produção escrita chamam a atenção. Em primeiro lugar, a larga presença de resenhas críticas: trinta e uma ao todo, nesse conjunto de cento e vinte e um títulos, ou seja, cerca de um

\footnotetext{
23 "Em Oxford, por exemplo", anota Graham, "havia uma forte tradição que combinava história da filosofia com filosofia, mas mesmo ali, enquanto os mesmos filósofos frequentemente estudavam problemas contemporâneos e textos antigos (como W. D. Ross e Gilbert Ryle), eles não se sentiam necessariamente compelidos a aplicar métodos modernos aos autores antigos. Em Cambridge, por outro lado, os que se ocupavam da filosofia antiga estavam principalmente no campo dos estudos clássicos, como F. M. Cornford e W. K. Guthrie, que, embora fossem scholars de talento e com bagagem filosófica significativa, eram indiferentes ou contrários à exploração de métodos filosóficos modernos". Cf., para esta nota e para a citação no corpo do texto, GRAHAM, D. W. Introduction. In: VLASTOS, G. Studies in Greek philosophy, v. I, The Presocratics, edited by Daniel W. Graham. Princeton: Princeton University Press, 1993, p. xvii-xviii.

${ }^{24}$ VLASTOS, G. The Third Man Argument in the Parmenides. Philosophical Review, v. 63, p. 319-349, 1954, republicado em ALLEN, R. E. (Ed.). Studies in Plato's Metaphysics. London: Routledge \& Kegan Paul, 1965, p. 231-261.

${ }^{25}$ Segundo o próprio Vlastos, este artigo foi a monografia mais duramente criticada neste domínio nos anos 50: dos vintes e um estudos publicados posteriormente sobre o argumento do Terceiro Homem, quase todos trazem uma crítica de suas análises. Cf. SIMP, p. 5.
} 
quarto do total publicado. Esse detalhe, aparentemente anódino, revela a preocupação e o interesse que Vlastos tinha pelo que estavam fazendo os outros que pesquisavam no terreno de suas especialidades. Significa ainda tempo empenhado - e sabemos o que pode custar em esforço e dedicação uma resenha bem feita; no caso de Vlastos, uma resenha podia facilmente chegar a trinta páginas - em se manter atualizado e contribuir efetivamente para um debate de ideias em vista do qual ele aceitava, mais do que com simples humildade, com genuíno espírito científico, mudar o curso ou as conclusões do próprio trabalho. Nesse sentido vale recordar o que contam seus contemporâneos que puderam conhecê-lo, como o próprio Graham citado há pouco, ou Richard Kraut da Universidade de Chicago. Eles lembram a atenção e o zelo com que Vlastos mantinha, mesmo ao preço de uma saúde já vacilante, uma assídua correspondência com - a expressão é de Graham - "literalmente centenas de estudiosos", fossem eles autoridades bem estabelecidas ou estudantes em início de carreira, através da qual ele expunha e discutia escrupulosa e pormenorizadamente seu próprio trabalho assim como o de seus correspondentes. Graham lembra ainda, de passagem, que Vlastos sempre se constrangia e se desculpava quando demorava mais do que uns poucos dias para responder uma carta recebida. Nesse intercâmbio, Vlastos não só influenciou como se deixou influenciar. Um exemplo para a primeira situação é o débito que Michael Stokes reconhece para com a correspondência estabelecida com Vlastos na elaboração de certos aspectos de seu One and Many in Presocratic Philosophy, ${ }^{26}$ uma correspondência que, ao que parece, interveio em um momento em que os pré-socráticos não mais constituíam o centro das pesquisas de Vlastos.

Para a segunda situação, a da influência dessas trocas sobre a obra de Vlastos, ${ }^{27}$ um outro exemplo, além de sua passagem pela Universidade de St. Andrews referida acima, é a série de artigos tratando principalmente do Sócrates de Platão que ele escreveu a partir do final dos anos setenta, motivado em parte pelo livro de seu mais célebre aluno, Terence Irwin, Plato's Moral Theory: The Early and Middle Dialogues (Oxford: Oxford University Press, 1977; reformulado e republicado, anos mais tarde, com o título Plato's Ethics [Oxford: Oxford University Press, 1995]). O próprio Vlastos reconhece, anos mais tarde, que o que despertara sua reflexão sobre Sócrates foi "um novo e estupendo livro", que é na verdade parte da tese defendida por Irwin em Princeton sob a orientação do próprio Vlastos: "a mais longa tese, e também a melhor, escrita sob a minha orientação", ele diria, acrescentando: "lê-la na sua forma definitiva (...) se revelou uma das mais instrutivas experiências da minha vida". Com certeza não é todos os dias que um professor se expressa com termos assim a respeito

\footnotetext{
${ }^{26}$ Cf. STOKES, Michael. One and Many in Presocratic Philosophy. Cambridge, Mass.: Harvard University Press, 1971 (cf. p. 40, n. 61). Os pontos nos quais a colaboração de Vlastos teria sido essencial para o trabalho de Stokes foram retomados e desenvolvidos algum tempo depois por BARNES, Jonathan. The Presocratic Philosophers. London: Routledge \& Kegan Paul, 1979, v. I.

${ }^{27}$ Vlastos datava o nascimento do novo estilo em filosofia antiga com o advento do livro de Richard Robinson, Plato's Earlier Dialectic (Ithaca, New York: Cornell University Press, 1941; segunda edição: Oxford: Clarendon Press, 1953), uma obra seminal que ele mesmo, Vlastos, reconhecia ter exercido profunda influência em seu próprio trabalho.
} 
do trabalho de um aluno. Mas no ano seguinte ao que o livro aparece, Vlastos publica no Times Literary Supplement uma resenha em que critica essencialmente a ideia, sustentada por Irwin, segundo a qual a filosofia moral de Sócrates, no que tange à relação entre virtude e felicidade, é marcada por um forte instrumentalismo, termo pelo qual Irwin escrupulosamente substitui utilitarismo, muito marcado pela filosofia inglesa do século XIX. Irwin responde às críticas no mesmo periódico e estabelece-se a partir daí entre os dois uma correspondência aberta que durará quase seis meses, a maior troca de ideias filosóficas registradas na seção de cartas do Times Literary Supplement, como relata Vlastos na introdução de seu Socrates, ironist and moral philosopher, ele afirma ainda, parecendo lembrar que recobrara a lucidez numa situação que, movida por sua própria paixão (e ao que tudo indica também pela de Irwin), encaminhava-se para um absurdo já meio cômico: "Irwin escreveu sua primeira carta em março, eu escrevi a minha última em setembro. A correspondência acabou quando eu disse na minha carta de setembro que seria a última de minha parte. Ele então, por cortesia, me deixou a última palavra". ${ }^{28}$

A outra característica, já mencionada, que se observa na produção vlastiana é o fato de que muitos de seus textos - a maioria, talvez - tenham sido republicados, em alguns casos, mais de uma vez. Além disso, esses mesmos textos eram já frequentemente o produto de seminários, cursos ou outras exposições orais. Assim as já evocadas Gifford Lectures na Universidade de St. Andrews, de 1981, estão também na origem do artigo "The Socratic elenchus" publicado em $1983^{29}$ (um artigo, aliás, que lhe valeu a aprovação de Donald Davidson), e republicado postumamente em 1994. O procedimento se explica (obviamente em relação às republicações levadas à cabo pelo próprio Vlastos), em parte, pela necessidade, sentida pelo autor ou por seus editores, de divulgar de forma mais ampla algum trabalho menos acessível ou incluí-lo em novas coletâneas, do próprio autor ou de mais de um autor, em vista da composição de um todo orgânico garantido por alguma unidade temática (lembremos que os bancos de dados com textos integrais digitalizados, onde se pode obter mesmo volumes antigos dos principais periódicos é coisa recente). Seria esse o caso, por exemplo, da coletânea de ensaios Socratic Studies, editados por Myles Burnyeat (Cambridge: Cambridge University Press, 1994), que em eco aos Platonic Studies (Princeton: Princeton University Press, 1973, republicado com acréscimos em 1981), dão, na verdade, sequência ao SIMP, conforme o projeto imaginado pelo próprio Vlastos ${ }^{30} \mathrm{e}$ os dois volumes

\footnotetext{
${ }^{28}$ SIMP, p. 7, n. 30.

${ }^{29}$ VLASTOS, G. The socratic Elenchus. Oxford Studies in Ancient Philosophy, v. 1, p. 27-58, 1983 (republicado em VLASTOS, G. Socratic Studies. Ed. Myles Burnyeat. Cambridge: Cambridge University Press, 1994, p. 1-37).

${ }^{30}$ É interessante observar que a última das seis seções principais dos Socratic Studies, intitulada "Epilogue: Socrates and Vietnam", não deveria, em princípio, integrar o volume. No projeto original, concebido por Vlastos, em seu lugar deveria figurar um artigo sobre o Lysis, que infelizmente restou inacabado, num estágio da redação que, segundo o próprio editor da coletânea, Myles Burnyeat, não permitia a sua publicação. A escolha da substituição, conforme explica o mesmo Burnyeat, se justificava pelo fato de que este epílogo se coadunava muito bem com o epílogo de SIMP, "Felix Socrates".
} 
dos Studies in Greek Philosophy, vol. I, The Presocratics e vol. II, Socrates, Plato, and their Tradition (Princeton: Princeton University Press, 1993 e 1995, respectivamente), que como obras póstumas, conservando tanto quanto possível a forma original dos textos, cumpriam ainda uma função memorialística. Por outro lado, constata-se que essas republicações - melhor: essas reedições - traziam frequentemente modificações mais ou menos importantes com relação aos originais. Os editores de Vlastos comentam que ele era quase obsessivo em atualizar e revisar seus escritos. Myles Burnyeat conta, por exemplo, que o seu trabalho de edição pode se beneficiar bastante das cópias que Vlastos possuía de seus próprios textos, que traziam nas margens anotações substanciais. Por outro lado, Daniel Graham explica que um dos maiores obstáculos ao lidar com o espólio intelectual de Vlastos era justamente a dificuldade de identificar os itens do seu repertório: "o professor Vlastos jamais manteve uma bibliografia compreensiva de suas numerosas e multifacetadas publicações" ${ }^{31}$ O professor Vlastos, podemos suspeitar, jamais foi obrigado a manter atualizado algo comparável ao nosso "Currículo Lattes".

Seria absurdo pensar que Vlastos reescrevesse e republicasse seus artigos para remediar alguma esterilidade intelectual momentânea em vista de certas imposições e exigências institucionais. Também me parece difícil imaginar que a Universidade de Princeton, ou de Cornell, ou de Berkeley, ou de Harvard (e estamos nos Estados Unidos, epicentro do capitalismo mundial), ou de Cambridge, ou de St. Andrews na Escócia, ou a Queen's University do Canadá, onde ele trabalhou no começo da carreira, lhe impusessem alguma quota inflexível de produtividade. As exigências, necessárias e benéficas, se fazem obviamente por outros lados, e sempre em contrapartida das condições de trabalho oferecidas. Em todo caso, de modo aparentemente paradoxal, considerando o reescritor obsessivo que foi - e aí bem se vê o especialista da ironia socrática mimetizando seu objeto de estudo -, Vlastos escreve, na introdução de SIMP, a respeito da tarefa de rever o próprio trabalho: "Em alguns trabalhos anteriores eu cometi erros que eu jamais tentei atualizar para me retratar. A escavação arqueológica dos próprios erros é uma atividade entediante que denota alguma presunção”. Mas no exercício de uma autocrítica incomum, e demonstrando o seu compromisso com a profissão que escolheu e consideração pelas consequências do seu trabalho, ele prossegue: "Mas um desses erros é grande demais - verdadeiramente enorme - e com consequências a tal ponto nefastas, que não se pode deixá-lo no limbo das distrações perdoáveis". E anota: "Na medida em que esses escritos são ainda lidos por estudantes em formação, não é sem interesse corrigir o seu erro mais grave". ${ }^{32}$ Vlastos fazia aí referência à tese que ele sustentara, explicitamente na introdução de sua edição do Protágoras (1956) e implicitamente no seu artigo "The paradox of Socrates" (1957), para equacionar, mantendo-se fiel à atopia de Sócrates, a sua afirmação de ignorância e a negação dessa ignorância subentendida em seu método de investigação. O erro de Vlastos estaria, segundo ele mesmo afirma, em concluir uma "suspensão do julgamento" por Sócrates a

\footnotetext{
${ }^{31}$ D. W. Graham, em VLASTOS, G. Studies in Greek Philosophy, v. I cit., p. IX.

32 SIMP, p. 3.
} 
partir da renúncia à toda certeza epistêmica conduzida por seu próprio método investigativo; Vlastos confirmava assim o ponto de vista de Cícero, para quem Sócrates teria, de certa forma, antecipado a posição de dois dos principais escolarcas da Nova Academia, Arcesilau e Carnéades. O que naquela época Vlastos não foi capaz de ver - e é esta a correção que ele propõe para sua tese - é que Sócrates, renunciando à toda certeza, não renuncia à busca do saber, sustentando justamente que saber é virtude.

A disposição de Vlastos em retomar com novo fôlego seus trabalhos já dados ao público, não podendo ser posta na conta de uma impensável "mais-valia" do trabalho intelectual, não deve contudo nos iludir, como se fosse a simples mea culpa de um espírito generoso ou o exercício de uma humildade ingênua. A disposição de se corrigir vem de par e em igual medida com a disposição de apontar os erros - e, sempre que for o caso, os acertos - no trabalho dos outros. Nesse sentido, Vlastos podia às vezes substituir a ironia elegante de certas ocasiões por um sarcasmo mau humorado que ele punha a serviço da crítica. Assim, em reação às objeções com que Donald Morrison, num artigo de 1987, intitulado com algum atrevimento, “On professor Vlastos' Xenophon”, se opunha ao que ele considerava uma hipervalorização do testemunho de Platão em detrimento do de Xenofonte no que concerne à reconstrução do Sócrates histórico, Vlastos escreveu, pondo os pingos nos is:

Fico muito feliz em ver que Donald Morrison leva suficientemente a sério algumas coisas que eu afirmei trinta anos atrás, num artigo de semi-vulgarização [33], a ponto de achar que vale a pena refutá-las agora em uma revista especializada. Será que eu devo ser acusado de ter induzido em erro Santas $\left[{ }^{34}\right]$ e Kraut $\left[{ }^{35}\right]$, como ele pensa que eu fiz? Eu não acredito. Se um ou outro desses excelentes eruditos endossaram uma opinião errada a respeito de Xenofonte, apoiados unicamente naquilo que eu disse - coisa de que eu duvido muito eles é que devem se explicar. ${ }^{36}$

${ }^{33}$ Vlastos se referia provavelmente ao já mencionado "The Paradox of Socrates", publicado no Queen's quarterly em 1957. Este artigo forneceu o substrato para a resenha do livro de John Gould, The development fo Plato's ethics, de 1955, uma resenha a que Vlastos deu o título de "Socratic knowledge and platonic 'pessimism"', Philosophical Review, v. 66, p. 226-238, 1957, e foi republicada em The philosophy of Socrates: a collection of critical essays, de 1971 (p. 1-21), de que o próprio Vlastos foi o editor. O livro de Gould foi duramente criticado por Gerasimos Santas que foi, por sua vez, criticado por Morrison que via nele uma adesão à interpretação de Vlastos.

${ }^{34}$ SANTAS, Gerasimos. The Socratic paradox. The Philosophical Review, v. 73, p. 147-164, 1964.

${ }^{35}$ Cf. KRAUT, R. Socrates and the State. Princeton: Princeton University Press, 1984. Mas convém lembrar que Richard Kraut demonstrou, em mais de uma ocasião, ser bastante reticente com relação às posições de Vlastos: cf. KRAUT, R. Comments on Vlastos' The socratic elenchus. Oxford Studies in Classical Philosophy, p. 59-70, 1983, e a sua resenha de SIMP (Philosophical review, v. 101, p. 353-358, 1992), publicada alguns meses depois da morte de Vlastos, em que ele lamentava o fato de que "não poderia mais se beneficiar dos 'erros' [mistakes, entre aspas] do amigo' (p. 354).

${ }^{36}$ SIMP, p. 14. 
Essa era apenas mais uma pequena batalha de uma guerra antiga que opunha, de um lado da trincheira, Vlastos e Irwin, e, do outro, mas sob bandeiras diferentes (e em momentos diferentes) Morrison e Strauss, ${ }^{37}$ que buscavam reabilitar histórica e filosoficamente um autor cujo destino tinha sido, durante muito tempo, o de ser menor: em história menor do que Tucídides, em filosofia menor do que Platão. Para Morrison, o Sócrates de Xenofonte seria mais verdadeiro e mais completo do ponto de vista biográfico do que o de Platão, enquanto para Strauss, que partia de uma leitura ferrenhamente imanentista dos textos, Xenofonte seria um autor fundamental para a formação da filosofia política. O juízo de Vlastos, como se sabe, era muito diferente:

"Pode-se dificilmente conceber um homem que em matéria de gosto, temperamento e aparelhamento crítico (ou falta dele) fosse tão diferente quanto o foi Xenofonte dos membros influentes do círculo dos íntimos de Sócrates. É claro que a maior diferença é que homens como Platão, Aristipo, Antístenes, Euclides e Fédon eram filósofos que sustentavam, cada um deles, doutrinas vigorosamente originais - e um dentre eles era realmente um grande filósofo -, enquanto Xenofonte, esse escritor de talentos variados, inovador e criador de gêneros literários totalmente novos [Vlastos pensa aqui na originalidade do "romance pedagógico pseudo-histórico que é a Ciropedia e nas memórias militares da Anábase"], estava longe de ser tão versado ou tão dotado para a filosofia quanto eles". ${ }^{38}$

Vlastos se inscrevia assim na mesma linha de leitura de Bertrand Russell, um dos colaboradores de Whitehead, seu antigo diretor de estudos em Harvard, que explicava o testemunho de Xenofonte sobre o ensinamento de Sócrates com a seguinte comparação pouco lisonjeira:

Quando um imbecil transmite as palavras de um homem inteligente, ele sempre falha em exatidão, pois ele traduz inconscientemente o que ele ouve para chegar a alguma coisa que ele possa compreender. ${ }^{39}$

$\mathrm{Na}$ verdade, Vlastos atenua os termos do juízo de Russell, lembrando justamente as qualidades de Xenofonte como escritor e general, mas nega-lhe a têmpera do filósofo:

\footnotetext{
${ }^{37}$ STRAUSS, L. Xenophon's socratic discourse. Ithaca: Cornell University Press, 1970 e STRAUSS, L. Xenophon's Socrates. Ithaca: Cornell University Press, 1972. Cf. a resenha de T. Irwin desse último em Philosophical Review, v. 83, p. 409-413, cujas críticas Vlastos mais tarde incorpora por sua própria conta. ${ }^{38}$ SIMP, p. 141.

${ }^{39}$ RUSSELL, B. History of Western Philosophy. New York, 1945, p. 83. Russell afirma ainda, comparandose talvez a Sócrates e considerando-se um homem inteligente, que ele preferiria ver suas próprias teorias expostas por um filósofo hostil às suas ideias do que por um amigo que não entendesse nada de filosofia.
} 
Xenofonte está longe de ser um imbecil. No domínio da ficção pedagógica literária, sua Ciropedia é uma empresa tão inteligente quanto tudo o que nos foi transmitido neste gênero desde a Antiguidade clássica. Tanto nessa obra quanto em outros contextos, Xenofonte dá provas de um julgamento perspicaz sobre o mundo e sobre os homens. Se eu fosse um daqueles dez mil gregos deixados sem comando nas regiões selvagens da Anatólia, em busca de um comandante em quem se pudesse confiar para trazê-los em toda segurança para a civilização (...), eu teria votado em Xenofonte e não em Russell. ${ }^{40}$

O curioso nessa história é que, anos mais tarde, em 1994, Donald Morrison publica um estudo intitulado "Xenophon's Socrates as Teacher", ${ }^{41}$ em que faz apenas uma menção rápida à polêmica com Vlastos, precisamente em torno do conceito de "ironia complexa” (que ele crítica de uma perspectiva semelhante à de Kraut). Ao fim do estudo, entretanto, registra em nota, entre outros agradecimentos, sua dívida para com Vlastos por seus comentários preciosos aos seus primeiros esboços. E agradece ainda, vale mencionar, à Fundação Alexander von Humboldt, de Berlim, pelo patrocínio durante os estágios iniciais da pesquisa, entre os anos de 1986-1987, ou seja oito anos antes da publicação de seus resultados.

A primeira constatação a que esse breve percurso nos leva é a de que essas duas características da produção vlastiana - a elaboração de resenhas críticas e a reescritura dos próprios trabalhos - apontam na mesma direção. Resenha e reescritura são, nesse caso, movimentos de um mesmo impulso, que corresponde de certa forma a uma tarefa eminentemente socrática, consubstanciada nas formas institucionais da prática filosófica atual; trata-se enfim de passar em exame a si mesmo e aos outros. Nesse sentido, a retratação não deve vir da simples modéstia, como a crítica não será produto da vaidade; também o elogio nada terá a ver com a bajulação ditada por uma ou outra conveniência. Por outro lado, posto que o meio dessa dupla epiméleia ainda é a linguagem, o que se põe em marcha é o genuíno exercício da parrésia. Não a parrésia política - melhor: a parrésia democrática - de que nos fala Demóstenes, que pode aliás degenerar de um útil "dizer tudo" para um desregrado "dizer qualquer coisa", numa espécie de "tersitismo" sem propósito, para revalidar uma expressão forjada por Norberto Bobbio. Também não se trata da parrésia dos diretores de consciência com prerrogativas divinas, que fundamenta a prática cristã da confissão e da penitência. Mas a parrésia que, segundo Michel Foucault, desponta com o próprio Sócrates, para ser reformulada e codificada mais tarde pelo epicurista Filodemo de Gadara em seu Perìparresías. Essa parrésia, enquanto instrumento da reforma moral, é o elo forte que liga um círculo de amigos.

Ao fim da introdução de seu SIMP, Vlastos escreve estas linhas que, por seu otimismo frustrado, vibram hoje com alguma melancolia: "eu cometi erros no passado, eu

${ }^{40}$ SIMP, p. 144.

${ }^{41}$ MORRISON, D. Xenophon's Socrates as Teacher. In: VANDER WAERDT, P. A. (Ed.). The Socratic Movement. Ithaca: Cornell University Press, 1994, p. 181-208. 
cometerei ainda outros, sem dúvida nenhuma, no futuro. Qualquer um que mos indique será meu amigo". ${ }^{42}$

Ao fim desse percurso, convém insistir que a produção bibliográfica de Vlastos coloca em evidência a natureza própria do trabalho intelectual, que nosso autor obviamente compreendeu e que parecem ter compreendido as instituições a que ele esteve ligado. Voltemos ainda um momento ao ponto de onde parti, a gênese de seu mais importante livro, nos termos de seu próprio testemunho. Ele nos conta que naquele ano de 53, livre para estudar a filosofia de Platão como bem entendesse, ele deu-se assim mesmo um objetivo claro, movido por razões "mais ou menos ridículas": conseguir aquilo que no círculo universitário americano é um requisito para a respeitabilidade, "um verdadeiro livro, impresso e encadernado (eu estava já no meio de minha carreira)". "Eu suei água e sangue”, ele prossegue, "e, como previsto, antes do fim do ano, um manuscrito de extensão necessária pousava pronto sobre a minha mesa de trabalho. Mas no momento de empacotá-lo para expedi-lo, eu parei um momento para dar uma última lida, calmamente, com um olho crítico (...). Eu o li do começo ao fim, e antes mesmo de acabar, um mal-estar no estômago - um signo socrático? - me dizia que aquilo não valia a tinta e o papel. Sem dúvida eu havia respondido corretamente às questões que eu tinha colocado - mais ou menos as mesmas que os especialistas naquele domínio tinham formulado no curso do meio século precedente. E no entanto ele não valia nada. Por quê? Se eu pudesse naquela época emitir o julgamento que eu tenho hoje a respeito desse trabalho, eu teria dito que a estranheza de Sócrates teria me escapado. A vaga intuição que eu tive, um instinto mais do que um juízo racional, me convenceu que o melhor a fazer com esse manuscrito era jogá-lo no lixo. Foi o que eu fiz. Um ano perdido? De jeito nenhum". ${ }^{3}$ O fruto desse trabalho surgiu, amadurecido em sua forma e conteúdo, trinta e sete anos depois. Vlastos parece mesmo não ter perdido nada e a história da filosofia só teve a ganhar.

\footnotetext{
42 SIMP, p. 35. Mas o tipo de parrésia a que Vlastos parece aspirar aqui assume um contorno inesperado, na medida em que inverte as fases de seu funcionamento: a amizade não é condição para o exercício da parrésia, mas o seu produto.

${ }^{43}$ SIMP, p. 12. Vale lembrar que esta não foi a única vez em que Vlastos deu provas de uma exigência superlativa com relação ao próprio trabalho, dispondo-se a "sacrificar" uma publicação iminente. Segundo relata Daniel Graham (in: VLASTOS, G. Studies in Greek Philosophy, v. I, cit. P. xvi), no final dos anos 1930, Vlastos trabalhava na elaboração de um livro intitulado Religion and the State in Plato, que refletia os seus vários interesses na época. Vlastos decidiu que este trabalho não estava pronto para publicação, e o manuscrito ficou esquecido em uma gaveta. Mais uma vez, não se trata de um trabalho perdido, já que a pesquisa realizada projeta-se sobre o resultado de outras publicações.
} 


\section{REFERÊNCIAS}

BARNES, J. The Presocratic Philosophers. London: Routledge \& Kegan Paul, 1979. v. I.

GRAHAM, D. W. Introduction. In: VLASTOS, G. Studies in Greek Philosophy. The Presocratics. Princeton: Princeton University Press, 1993. v. I, p.xvii-xviii.

GRAHAM, D. W. Bibliography; The Works of Gregory Vlastos. In: VLASTOS, G. Studies in Greek Philosophy. v. II: Socrates, Plato and their Tradition, 1996. p. 325-330.

IRWIN, T. Review of Leo Strauss' Xenophon's Socrates. Philosophical Review, v. 83, p. 409413, 1974.

KRAUT, R. Socrates and the State. Princeton: Princeton University Press, 1984.

KRAUT, R. Comments on Vlastos' The socratic elenchus. Oxford Studies in Classical Philosophy, p. 59-70, 1983.

MORRISON, D. Xenophon's Socrates as Teacher. In: VANDER WAERDT, P. A. (Ed.). The Socratic movement. Ithaca: Cornell University Press, 1994. p. 181-208.

ROBINSON, Richard. Plato's Earlier Dialectic. Oxford: Clarendon Press, 1953 [1a. ed.1941].

RUSSELL, B. History of Western Philosophy. New York, 1945.

SANTAS, G. The Socratic paradox. The Philosophical Review, v. 73, p. 147-164, 1964.

SCHELLING, F. W. J. Briefe an und von Hegel. ed. J. Hoffmeister. Hambourg: Meiner, 1969, t. I.

STOKES, Michael. One and Many in Presocratic Philosophy. Cambridge, Mass.: Harvard University Press, 1971.

STRAUSS, L. Xenophon's socratic discourse. Ithaca: Cornell University Press, 1970.

STRAUSS, L. Xenophon's Socrates. Ithaca: Cornell University Press, 1972.

VLASTOS, G. Whitehead, critic of abstractions (being the story of a philosopher who started with science and ended with metaphysics). The Monist, v. 39, p. 170-203, 1929.

VLASTOS, G. Ethics an physics in Democritus II. Philosophical Review, v. 55, p. 53-64, 1946.

VLASTOS, G. Parmenides' theory of knowledge. Transactions and Proceedings of the American Philological Association, v. 77, p. 66-77, 1946.

VLASTOS, G. Solonian Justice. Classical Philology, v. 41, p. 65-83, 1946.

VLASTOS, G. On the pre-history in Diodorus. American Journal of Philology, v. 67, p. 51-59, 1946.

VLASTOS, G. The Third Man Argument in the Parmenides. Philosophical Review, v. 63, p. 319-349, 1954. (republicado em ALLEN, R. E. (Ed.). Studies in Plato's Metaphysics. London: Routledge \& Kegan Paul, 1965, p. 231-261). 
VLASTOS, G. Plato's Protagoras. New York: Liberal Arts Press, 1956.

VLASTOS, G. The paradox of Socrates. Queen's Quarterly, v. 64, p. 496-516, 1957-1958.

VLASTOS, G. Isonomia politiké. In: MAU, J.; SCHIMIDT, E. G. (Ed.). Isonomia: Studien zur Gleichheitsvorstellung im griechischen Denken. Berlin: Akademie-Verlag, 1964. p. 1-35.

VLASTOS, G. Anamnesis in the Meno. Dialogue, v. 4, p. 143-167, 1965.

VLASTOS, G. Creation in the Timaeus: is it a fiction? In: ALLEN, R. E. (Ed.). Studies in Plato's Metaphysics. London: Routledge \& Kegan Paul, 1965, p. 401-419.

VLASTOS, G. Degrees of reality in Plato. In: BAMBROUGH, R. New Essays in Plato and Aristotle. London: Routledge \& Kegan Paul, 1965, p. 1-19.

VLASTOS, G. Minimal parts in Epicurean atomism. Isis, v. 56, p. 121-147, 1965.

VLASTOS, G. Justice and psychic harmony in the Republic. Journal of Philosophy, v. 66, p. 505-521, 1969.

VLASTOS, G. Plato's “Third Man” Argument (Parm, 132 a1-b2). Philosophical Quarterly, v. 19, p. 289-301, 1969.

VLASTOS, G. Pre-Socratic philosophy. In: Encyclopedia Americana, v. 22, New York: Americana Corporation, 1969.

VLASTOS, G. Reasons and causes in the Phaedo. Philosophical Review, v. 78, p. 132-166, 1969.

VLASTOS, G. “Self-predication in Plato's later period”, Philosophical Review, v. 78, p. 74$78,1969$.

VLASTOS, G. Socrates on acrasia. Phoenix, v. 23, p. 71-88, 1969 (republicado em Studies in Greek Philosophy, v. II: Socrates, Plato and their tradition, edited by Daniel W. Graham. Princeton: Princeton University Press, 1995, p. 43-59).

VLASTOS, G. Justice and happiness in the Republic. In: (Ed.). Plato: A Collection of Critical Essays II: Ethics, Politics and Philosophy of Art and Religion. Garden City, New York: Doubleday \& Co., 1971. p. 66-95.

VLASTOS, G. Platonic Studies. Princeton: Princeton University Press, 1973.

VLASTOS, G. Graduate education in the Humanities: reflections and proposals. In: FRANKENA, W. (Ed.). The Philosophy and Future of Graduate Education. Ann Arbor: University of Michigan Press, 1980, p. 64-81.

VLASTOS, G. The socratic Elenchus. Oxford Studies in Ancient Philosophy, v. 1, p. 27-58, 1983 (republicado em VLASTOS, G. Socratic Studies. Ed. Myles Burnyeat. Cambridge: Cambridge University Press, 1994, p. 1-37).

VLASTOS, G. Happiness and virtue in Socrates' moral theory. Proceedings of the Cambridge Philological Society, n.30, 1984, p. 181-213 (republicado em Topoi, v. 4, p. 3-22, 1985). 
VLASTOS, G. Socrates. Proceedings of the British Academy, v. 74, p. 89-111, 1988.

VLASTOS, G. Socrates, Ironist and Moral Philosopher. Ithaca, New York: Cornell University Press, 1991.

VLASTOS, G. Socrate. Ironie et philosophie morale. Traduit de l'anglais par Catherine Dalimier. Paris: Aubier, 1994.

VLASTOS, G. Socrate. In: CANTO-SPERBER, M. (Dir.). Philosophie Grecque. Paris: P.U.F., 1998, p. 123-142 [1a ed. 1997].

VLASTOS, G.; DIXSAUT, M. Refutação. Tradução e introdução de Janaína Mafra. São Paulo: Paulus, 2012. 